\title{
The Relation of Cambial Zone Mechanical Strength to Growth and Irrigation of Almond [Prunus dulcis (Mill.) Webb.] Trees
}

\author{
Sunitha H. Gurusinghe and Kenneth A. Shackel ${ }^{1}$ \\ Department of Pomology, University of California, Davis, CA 95616 \\ Additional index words. shaker harvesting, shaker damage, water stress, stem water potential, stomatal conductance, \\ Ceratocystis fimbriata
}

\begin{abstract}
Commercial harvesting of almonds [Prunus dulcis (Mill.) Webb.] with mechanical shakers is economical, but may also cause severe damage to the cambial zone, leading to the establishment of a deadly cankerous disease, ceratocystis. Irrigation is often cut off for some period of time before harvest, anticipating a reduction in the damage as a result of an increased strength of adhesion within the cambial zone between the bark and the wood. Mechanical failure can occur in the cambial zone proper and in the differentiating cells on either side of the cambial zone. In this study the shear force per shear area in the cambial zone (cambial strength) was measured to represent mechanical failure due to shaker damage. Cambial strength of branches with intact bark tissues could be reversibly influenced by the level of tissue hydration, with high cambial strength associated with increased tissue hydration, presumably a result of an increase in the turgor of cambial zone cells. Methods of measuring cambial strength were developed for branches and trunks to avoid the effects of reversible turgor changes. Irrigation regimes imposed before harvest had a substantial and progressive influence on tree stem water potential, stomatal conductance, and growth rate of almond trees. Statistically significant levels of within seasonal differences in rate of growth, stomatal conductance and tree water deficits found under different irrigation regimes did not show any correlation with the within seasonal fluctuations in cambial strength. Cambial strength always showed a similar pattern and a similar magnitude of seasonal increase from spring to summer (as previous authors have reported), superimposed over the within seasonal fluctuations, despite significant differences in tree water stress. Therefore, this study suggests that irrigation cut off may be an ineffective practice for the purpose of increasing cambial strength.
\end{abstract}

Almond trees are commercially harvested using mechanical shakers, which are economical but may also cause tree damage. During shaking, compressive and shear forces are applied to the bark surface and these forces must be balanced by compressive and shear reactions in the cambial zone and by the resistance to tensile failure of the bark fibers (Diener et al., 1968; Fridley et al., 1970). Severe shaker damage separates the bark from the wood and exposes the cambial zone to infection by the fungus Ceratocystis fimbriata Ell. \& Halst., leading to ceratocystis (Mallet Wound) canker and premature tree death (De Vay et al., 1960, 1968).

The mechanical strength of the cambial zone has been studied by a number of researchers for purposes other than mechanical harvesting, such as debarking for pulp and paper (Fiscus et al., 1983; Einspahr et al., 1984; Moor and McMahon, 1986). In debarking studies, the failure zone was found to be in the cambial zone proper or at times on either side of phloem and xylem differentiating zones (Einspahr et al., 1984; Fiscus et a1., 1983). Hence, in this study, the cambial zone will be taken as including the cambium proper (all cells that can divide, Esau, 1965; Philipson and Ward, 1965) plus the cells undergoing differentiation before maturation. The maximum shear stress at cambial zone failure, which we term cambial strength, has been also called wood-bark adhesion (Fiscus et al., 1983), failure stress (Moor and McMahon, 1986), shear stress (Fridley et al., 1970), and bark strength (Brown et al., 1987). For intact bark on the tree trunk, shearing at complete failure involves bark and cambial zone components and has been called 'total tangential strength' by Fridley et al. (1970). If the

Received for Publication 18 Feb. 1994. Accepted for publication 29 July 1994. This work supported in part by a grant from the California Almond Board. The cost of publishing this paper was defrayed in part by the payment of page charges. Under postal regulationl, this papertherefore must be hereby marked advertisment solely to indicate this fact.

${ }^{1}$ To whom reprint requests should be addressed. force required to shear an isolated portion of bark from the trunk is determined, then the cambial zone component is measured, which we will refer to as cambial strength. Fridley et al. (1970) compared total strength (tangential) with cambial strength in prune (Prunus domestica L.) trees and found that cambial strength accounted for $50 \%$ to $70 \%$ of the total tangential strength over the duration of their study, which lasted 2 months. Both of these measurements of strength changed in parallel, demonstrating that the cambial strength component is a useful index of overall shear strength.

During winter, the cambial strength of 24 hardwood species was high (706-3006 $\mathrm{kPa}$ ), whereas, during spring, it was low (245-628 kPa) (Einspahr et al., 1984). This transition from winter to spring is well known to be associated with an increased ease of peeling (Fobes, 1957; Priestly et al., 1933; Schutt, 1960; Wilcox et al., 1954) of the bark from the wood, and it has been attributed to the resumption of growth of the tree. Based on this seasonal pattern of tree growth, many have presumed that the reciprocal of cambial strength is itself a direct measure of cambial activity and growth (Brown et al., 1987; Fridley et al., 1970; Madden, 1977). Reducing cambial growth and increasing cambial strength is the basis for recommendations (Brown et al., 1987; Fridley et al., 1970) that irrigation be cut off before shaker harvesting to reduce shaker damage in almond and other crops. Water stress is well known to reduce plant growth (Bradford and Hsiao, 1982), however, a reciprocal relationship between cambial strength and cambial growth has not been clearly shown to hold for different periods within a growing season, particularly with respect to water stress.

Bark moisture content has been commonly used as a measure of tree water status. Fridley et al. (1970) reported that during a 1-year period, a low moisture content was associated with high shear strength for data collected from monthly to trimonthly intervals on prune, almond, and peach (Prunus persica (L.) Batsch.), although 
no statistical treatment of their data was given. A reanalysis of their data showed that out of the three groups of French prune studied, two showed a very highly significant negative relationship $\left(R^{2}=\right.$ 0.91-0.93 at $P \leq 0.01$ ) between moisture content and bark strength. The remaining group of French prune, two groups of Texas almond, and the Dixon peach showed no statistically significant relationship. Therefore. it is important to reevaluate whether the proposed negative relationship of moisture content and cambial strength occurs within a growing season, particularly during the harvesting period. and whether it can be associated with irrigation related differences in tree water status. Moor and McMahon (1986) found statistically significant increases in the cambial strength of three species of eucalypts (Eucalyptus obliqua L., E. rubida $\mathrm{H}$. Deane \& Madden, and E. viminalis Labill) and pine [Pinus radiata (D.) Don] from spring to summer ranging from 50 to $270 \mathrm{kPa}$, but not all species showed statistically significant differences in bark moisture content (wet basis) over the same time period. In many studies across many tree types (Fridley et al., 1970), a significant increase in cambial strength from September to January has always been found, but no significant change in the moisture content was found. Therefore, moisture content may not be associated with cambial strength during the harvest period.

In irrigated and nonirrigated cherry trees in the summer, Brown et al. (1987) reported a negative relationship of cambial strength and moisture content at four levels of applied radial stresses. but no statistical significance was given. Reanalysis of their data showed that $R^{2}$ ranged from 0.10 to 0.47 and only one level of applied radial stress out of four was significant at $P \leq 0.03$. In addition to cambial strength, Brown et al. (1987) also related the strain angle (angular deformation of the bark at failure per unit bark thickness) with moisture content. At high moisture content, failure occurred at a high strain angle, whereas at low moisture content failure occurred at low strain angle at three different radial stresses tested. A similar reanalysis showed that their data gave a $R^{2}=0.04(P \leq 0.05)$ at the highest radial stress tested. but the other two radial stresses tested did not show any significant relationships $\left(R^{2}=0.20\right.$ and 0.16$)$. However, all of these relations were positive. Since the expected relation of stress and strain is positive (eg. Fridley et al., 1970), the overall weak statistical relation and opposite slopes of stress or strain with moisture indicate that there may in fact be no relation of moisture content to bark mechanical strength, at least for the ranges of moisture content studied by these authors.

One demonstration of a close relation of cambial strength and irrigation would be an increase in cambial strength after a period of no irrigation or, conversely, a decrease in cambial strength following irrigation. Fridley et al. (1970) actually found opposite effects; i.e., over two irrigation events in prunes, soil drying as evidenced by tensiometer measurements was associated with a very clear reduction in cambial strength. The two highest strength values $(1103 \mathrm{kPa}$ and $1138 \mathrm{kPa})$ were measured 3 days after the first irrigation and again 3 days after the second irrigation, respectively. The two lowest cambial strength values, 758 and $827 \mathrm{kPa}$, were obtained in the latter portion of soil drying (13 and 23 days of drying, respectively) following the first irrigation event. After the second irrigation. the cambial strength did not decrease with soil drying as in the previous drying cycle. This indicated that soil drying between irrigations had inconsistent effects on cambial strength. It is important to note that the second drying cycle, where the cambial strength did not decrease, also coincided with the normal time of a seasonal increase in cambial strength. Burton et al. (1986) carried out a comparison of shaker damage under three different irrigation treatments on 3-year-old cherry trees. They found severe damage with cracks or splits exposing the cambial zone using standard shaker equipment, and they recorded $6.5 \%$ severe damage in plots having continuous irrigation, $7.5 \%$ severe damage in the plots where water was cut off for two weeks before harvest, and $2.8 \%$ severe damage in a no irrigation treatment. With an improved shaker design, there was only $2.6 \%$ slight damage (no severe damage) with continuous irrigation compared to $2.6 \%$ of severe damage, attributed to misclamping, with a 2-week irrigation cutoff, and no damage in the no irrigation treatment. The reasons for attributing severe damage to misclamping for the improved method but not for the standard method were not stated. This study, and the results of Fridley et al. (1970) indicate that cambial strength may not be closely related to moisture status or irrigation cutoff, hence the existing data do not strongly support the idea that irrigation cut off increases cambial strength.

In this study, cambial strength and cambial growth rates were surveyed in a number of individual trees during a growing season and for trees under continuous irrigation vs. irrigation cut off conditions. The objective of the study was to determine therelation of cambial strength to cambial growth rate during the growing season and further to determine whether any observed reduction in growth rate due to tree water stress was associated with an increase in cambial strength.

\section{Materials and Methods}

This research was conducted at the Univ. of California, Davis (UCD), Pomology Experimental Orchards during 1989-1 993 using 7-year-old trees of 'Nonpareil' and 'Mission' almond varieties and at UCD Wolfskill experimental orchard in Winters, Calif., using 3-year-old 'Nonpareil' trees.

Measurements of cambial strength and daily growth in trunk and branches were made in nine flood irrigated trees in Davis. In

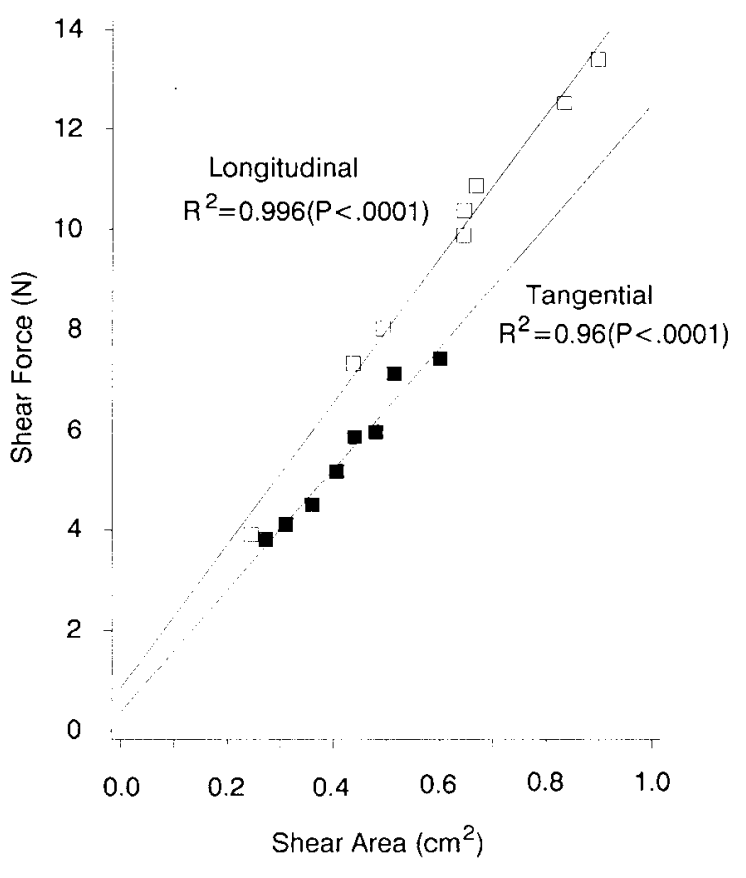

Fig.1. Shear force at failure for cambial zone sections with different cross sectional areas, prepared from a single trunk of an 8-year-old almond tree in the field. Cambial zone sections were sheared parallel to trunk axis (open symbols, longitudinal shear). or perpendicular to trunk axis (closed symbols, tangential shear). Linear regressions for each separate direction of shear are shown. Each point represents a single measurement. 


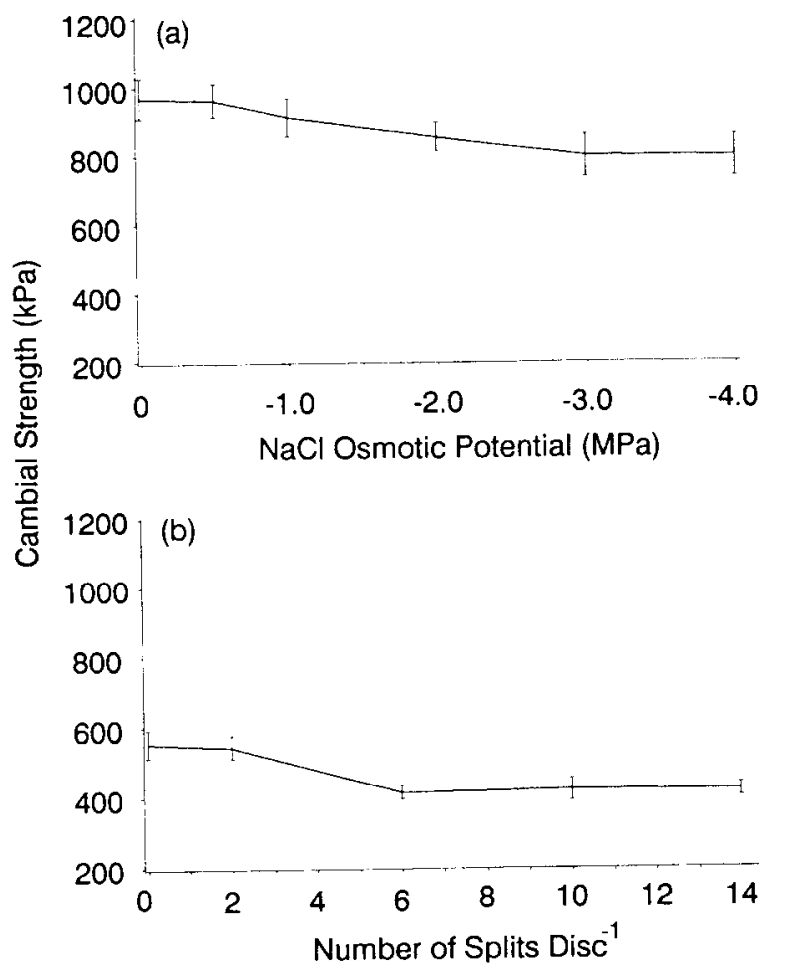

Fig.2. Reductions in the cambial strength of branch discs that were associated with (a) incubation of intact discs in a series of $\mathrm{NaCl}$ solutions or (b) increases in the number of bark splits on discs that were incubated in water. Samples in (a) were collected in November 1991 and samples for (b) were collected in June 1992. Each point represents a mean $(\mathrm{N}=30) \pm 2 \mathrm{SE}$.

Winters, trunk growth, cambial strength, tree water potential, and leaf conductance were measured in a microsprinkler Irrigated orchard that was divided into three irrigation regimes: wet, medium, and dry. Each regime had 40 test trees. The water applied to these regimes was adjusted as necessary to achieve three contrasting levels of tree water stress, as measured by midday stem water potential (McCutchan and Shackel, 1992). For a mature almond orchard with a cover crop in this location and year, the predicted water requirement from May to October using the California irrigation management information system (CIMIS) was $\approx 1100$ $\mathrm{mm}$ water. Our 3-year-old orchard was substantially less than mature, but by the end of the season $1400 \mathrm{~mm}$ of water had been applied to the wet regime, $400 \mathrm{~mm}$ to the medium, and $150 \mathrm{~mm}$ to the dry. The wet plots were irrigated 2 to 3 days a week. the medium plots were irrigated -1 day per week, and the dry plots were irrigated only -4 days for the whole growing season. Additionally, irrigation was discontinued on half of the trees in the wet regime on 4 Aug. 1993.

Tree water potential and leaf conductance. A mature leaf closest to the trunk or a main scaffold branch was enclosed by an aluminum-foil-covered, black plastic bag for a minimum $2 \mathrm{~h}$, and stem $\Psi$ (McCutchan and Shackel, 1992) was measured at midday with a pressure chamber (Soil Moisture Equipment Corp., Santa Barbara, Calif.). Conductance was measured on four well-exposed leaves per tree with a steady-state porometer (LI-1600; LI-COR, Lincoln, Neb.).

Measurement of cambial strength in trunks. A sharp knife was used to cut a grid of six tabs $(3 \times 2)$, and one tab with an area of 2 to $3.5 \mathrm{~mm}^{2}$ was left undisturbed on the tree while others were pried off with a knife point. The six tabs were oriented as three rows and two columns during longitudinal cambial strength measurement, and the tabs were oriented as two rows and three columns during tangential cambial strength measurement. A modified spring loaded force gauge (Western Industrial Supply, San Francisco) (0.2-1.5 $\mathrm{kg}$ ) equipped with a lever was used to apply force on the tab. The lever arm was placed on one side of the tab and pushed either longitudinally or tangentially by hand, and the force just required to shear the tab was determined. The speed of shearing was controlled by hand, but as found by Moor and McMahon (19X6). the speed used to apply the force did not affect the maximum shear force measured. Trunk cambial strength measurements were made at least $10 \mathrm{~cm}$ from any disturbance caused by the measurement of growth (see below) or previous measurement of cambial strength to minimize any localized wounding influences.

It was necessary to determine whether shear stress is independent of the size of the experimental unit (tab) area. From the definition of stress $(\sigma)$ we have $\mathrm{dF} / \mathrm{dA}=\sigma$ where $\mathrm{F}$ is force and $\mathrm{A}$ is area. Then, upon integration, we obtain, $\mathrm{F}=\sigma \mathrm{A}$. Thus, if shear stress is constant irrespective of the sire of the experimental unit, then we expect shear force to be linearly related to shear area with an intercept of $(0,0)$. Samples with a range of area were obtained from a single trunk, and for longitudinal and tangential shearing, the relation of tab shear area to shear force showed a linear
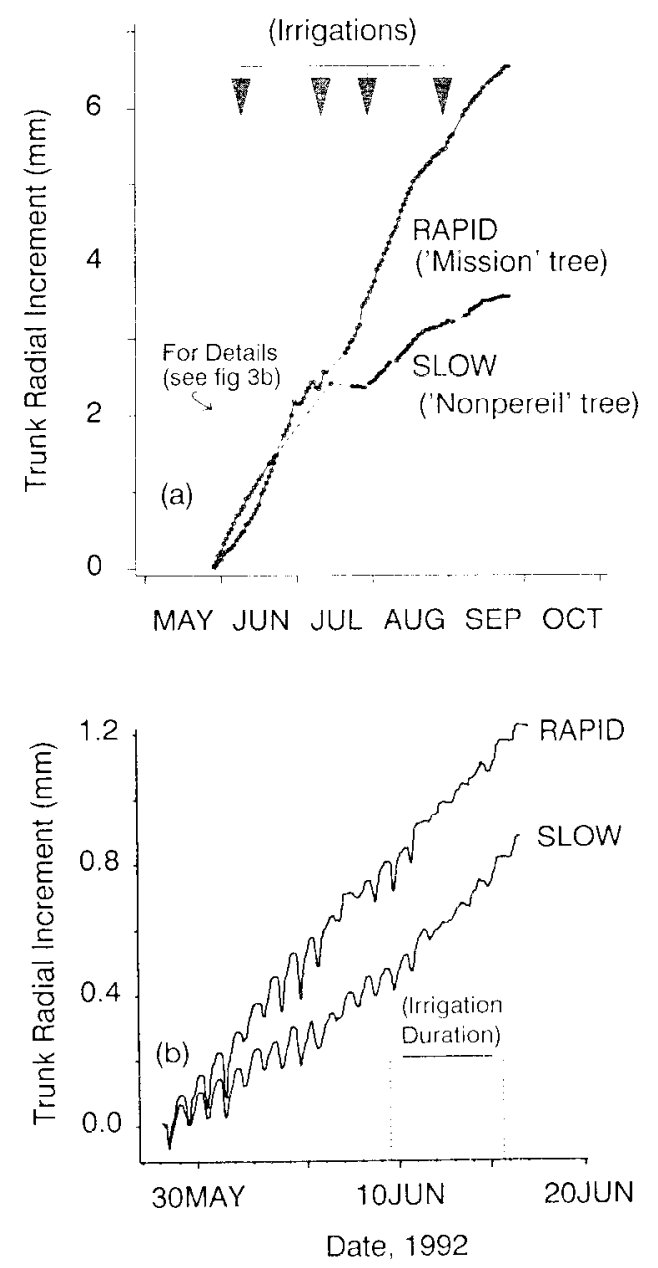

Fig. 3 (a) Examples of seasonal increases in the radius of tree trunks showing rapid or slow long-term growth. Dashed lines indicate missing data. Each dot represents the mean of all measurements taken over an entire day. (b) Details of the 1993. 29 May to 20 June period of trunk growth indicated in (a), showing diurnal oscillations of rapid and slow growing trees before and after a flood irrigation. which lasted 6 days, as indicated by the vertical dotted lines. Ticks on X-axis arc at midnight local time. 


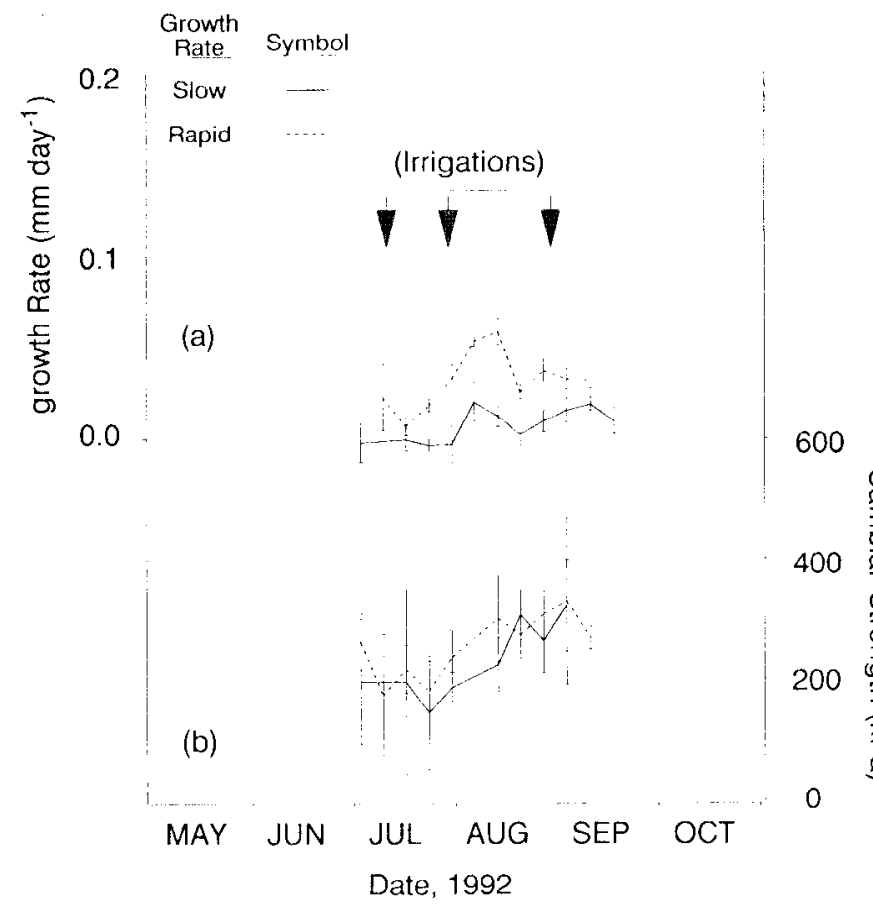

Fig.4. Trunk radial yrowth rate (a) and trunk cambial strength (b) lor rapid growing (3'Mission' and I 'Nonpareil') and slow growing (3'Nonpareil' and I "Mission') almond trees. (a) Measurements were taken daily, as in Fig. 3 a, and a weekly average was calculated. (b) Measurements were taken 2 days every week with a single measurement per tree. For growth rate and cambial strength cach bar represents a nean of four trees and itscorresponding \pm 2 st for cach weckly period.

relationship (Fig. 1). The high $R^{2}$ values (0.96-0.99) indicated good repeatability of the measurement and the intercepts $(0.98 \mathrm{~N}$ for longitudinal shear and $0.39 \mathrm{~N}$ for tangential shear) were not significantly different from zero (Fig. 1).

Measurement of cambial strength in branches. Discs 14 to 20 $\mathrm{mm}$ in diameter and 2 to $4 \mathrm{~mm}$ high were cut with a power saw from 2-year-old almond branches having a diameter of 14 to $20 \mathrm{~mm}$. The discs were placed on an aluminum plate having a circular hole, such that the bark portion of the disc rested on the edge of the hole and the entire wooden center of the disc was within the hole. A spring loaded force gauge. similar to that used for trunk measurements, with a modified flat end cylindrical head $(10 \mathrm{~mm}$ in diameter) was used to apply force to the center of the wood until separation of the wood from the bark occurred. The head of the tester was gently placed on the disc and force was applied at a slow speed to minimize movement of the disc. Cambial strength was calculated as $\mathrm{F} / \pi$ Dhwhere $\mathrm{F}_{\mathrm{s}}$ was the shear force, $\mathrm{D}$ was average diameter, and $\mathrm{h}$ was height of the disc. The relationship between $\mathrm{F}_{\mathrm{s}}$ and A for samples from a single branch was also linear, as in Fig. 1 (Gurusinghe. 1994).

Cambial strength in intact discs could be reversibly increased and decreased by hydrating and dehydrating branches in the laboratory (Gurusinghe, 1994). Hydrational changes in cell turgor, however, would be expected to cause radial compressive stresses in an intact disc, and thereby increase the cambial strength of the disc. Consistent with these expectations, when discs were incubated in solutions of increasing external osmotic concentration, cambial strength declined until about -3.0 $\mathrm{MPa}$, after which it was constant (Fig. 2a). The same pattern of decline was obtained for different osmotica ( $\mathrm{NaCl}, \mathrm{PEG}, \mathrm{Mannitol})$ and at different temperatures $(3,25$, and $30 \mathrm{C}$, data not shown), indicating a simple osmotic effect. Further evidence to show that radial compressive

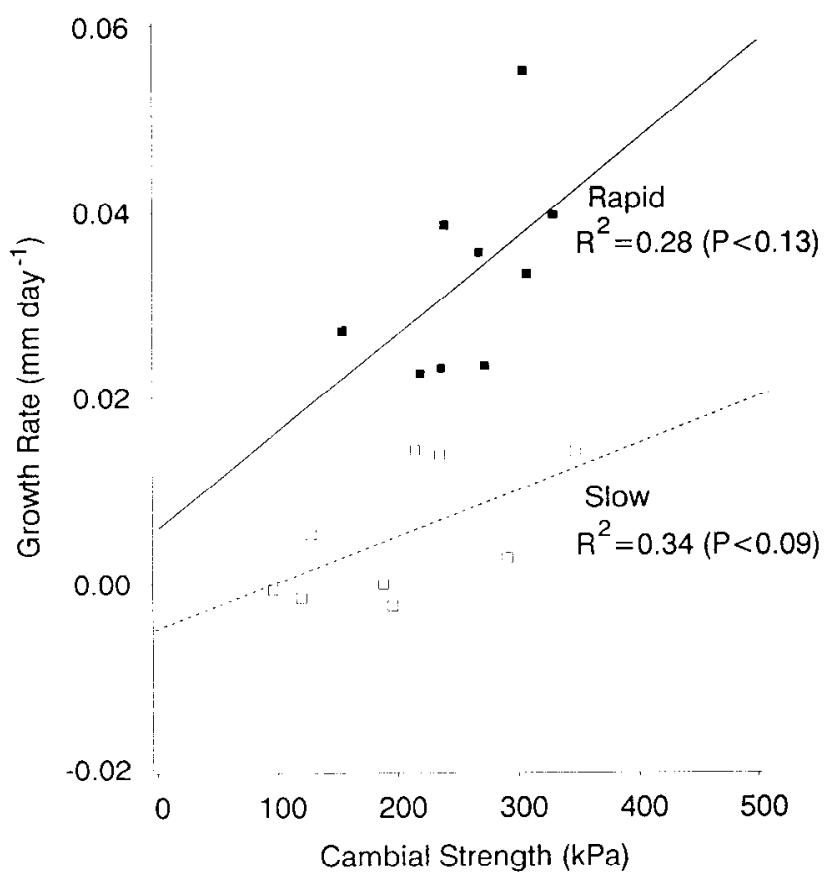

Fig. 5. Relation between weekly mean values of growth rate and cambial strength for the data shown in Fig. 4b, for the period July to September 1992. Linear regression are shown, but are not statistically significant. Closed symbols represent values for rapidly growing trees and open symbols represent values for slowly growing trees.

stresses increased intact cambial strength was obtained by various levels of splitting the bark ring to the depth of the secondary xylem. Splits were evenly spaced along the disc circumference and the disc was equilibrated in water. With increasing number of splits, cambial strength also declined to a constant value (Fig. 2b). This was similar to the increasing concentration of osmotica. These two separate ways of releasing compressive stresses were compared on the same stem, and the cambial strength of dehydrated discs (4.50 $\pm 36 \mathrm{kPa})$ was identical to that of the split discs $(450 \pm 64 \mathrm{kPa})$. In this study, for branch cambial strength measurements, overnight equilibration of discs in saturated $\mathrm{NaCl}$ at $25 \mathrm{C}$ was routinely followed for convenience.

Trunk and branch growth measurements. Diurnal and seasonal changes in branch and trunk diameter were measured using resistive position transducers (Spring Return Linear Sensor Module Resistor, Duncan Electronics, Costa Mesa, Calif.) connected to a datalogger (CR10; Campbell Scientific, Logan, Utah), which was programmed to measure at 20 -sec intervals and store average values over 10 -min periods. Under field conditions, transducers were accurate to $2150 \mu \mathrm{m}$ over their entire $12 \mathrm{~mm}$ range, but increased accuracy $( \pm 50 \mu \mathrm{m})$ could be obtained by limiting the range to 0 to $4 \mathrm{~mm}$. No detectable temperature or other environmental effects on the transducers were found even when they were exposed to direct sun under ambient conditions.

For branch measurements, the transducer was fixed to a rigid frame with an adjustable backstop and the backstop was tied to the branch. For trunk measurements, the transducer was fixed to a rigid post, and the base of the post was fastened to the trunk with screws extending into the wood. The point of growth measurement was $\approx 10 \mathrm{~cm}$ above the point of attachment to avoid possible artifacts due to wounding. This mounting of the transducer was similar to the mounting of the base of the lever dendrometer shown in Verner et al. (1962), except that, because of its light weight, there was no 
need to anchor the mount close to the point of growth measurement. For branch and trunk measurements, the tip of the sensor's sliding portion ended in a curved plastic surface to evenly distribute the force of the return spring $(65 \mathrm{~g})$ over a relatively large area $\left(3 \mathrm{~mm}^{2}\right)$. Growth rates and diurnal oscillations (see below) on opposite sides and at different heights above ground level on a single trunk (two trunks tested), were found to be identical; the same was found for growth and diurnal oscillations on opposite sides of branches (at $6 \mathrm{~cm}$ apart, in four test branches).

A metal meter tape was used to periodically measure trunk circumferential growth of the trees in Winters at two positions (25 and $30 \mathrm{~cm}$ ) above ground level.

\section{Results and Discussion}

Tangential cambial strength was found to be $15 \%$ lower than longitudinal cambial strength (Fig. I). This directional difference in strength properties (anisotropy) showed the highest strength parallel to the long cell axis of the majority of cambial initials (fusiform initials). Similar anisotropy has been universally found in all lignified woody tissues (Dinwoodie, 1981) and also in inner and outer bark tissues (Diener et al., 1968). These results suggest that the physical properties of the cell wall (cellulose microfibrillar orientation) (Dinwoodie, 1981), which are important in determining strength of materials such as wood, may be similarly important in the cambial zone for wood-bark adhesion.

Under field conditions the position transducers measured longterm growth (Fig. 3a) and short-term diurnal oscillations in trunk radius (Fig. 3b) similar to those reported by many others (Kozlowski, 1968). Clear differences in long-term growth were exhibited by individual trees, with some individuals showing sustained growth over the season, whereas others did not (Fig. 3a). Diurnal oscilla-

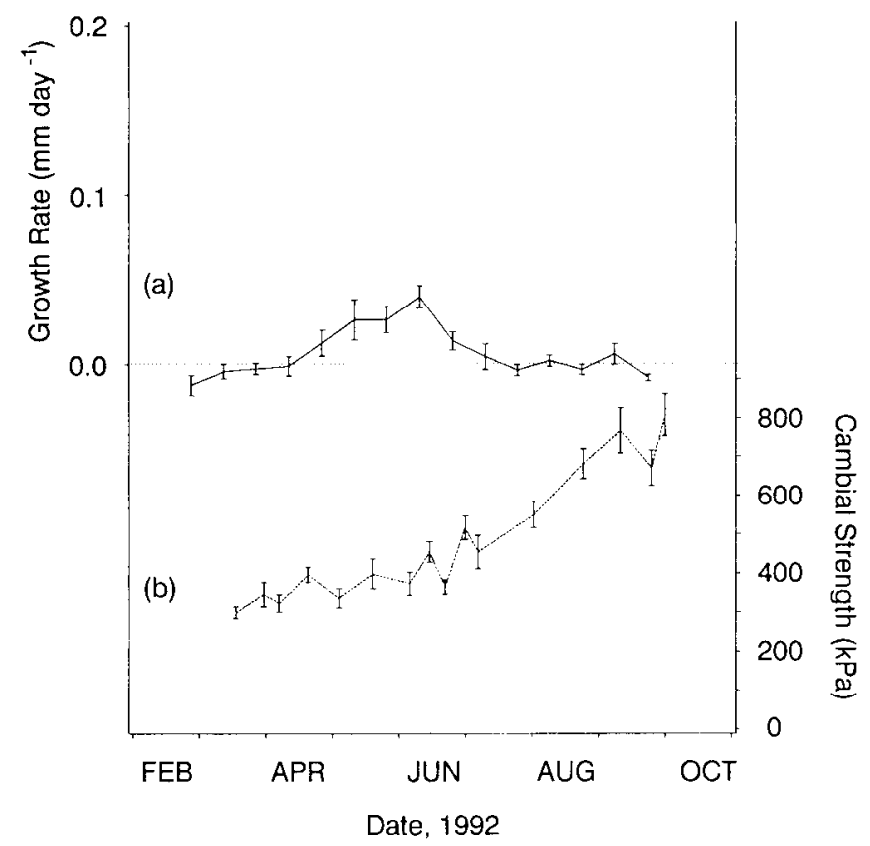

Fig. 6. Radial growth rate (a) and cambial strength (b) of 'Nonpareil' almond branches. (a) Measurements were taken daily, as in Fig. 3a, and biweekly averages were calculated. Each bar represents a mean of four to five branches and its corresponding \pm 2 SE for each biweekly period. (b) Disc measurements (30) from each branch were made weekly. Average per branch was calculated. Each bar represents a mean of two branches and the corresponding \pm 2 SE for each biweekly period. tions of rapid-growing individuals showed a clear progressive increase in growth compared to the slow-growing individuals (Fig. $3 b)$. After irrigation, growth is increased in slow- and rapidgrowing individuals by showing lesser diurnal shrinkage during midday (Fig. 3b). However, slow-growing individuals resume slow growth rates despite the influence of irrigation.

When trees were pooled into slow- and rapid-growing groups, sustained differences in cambial growth during the season were apparent, whereas differences in cambial strength were not (Fig. 4). Cambial growth rate of rapid-growing trees increased from July to August and cambial strength also increased, contrary to the expectation of a negative relation (Fridley et al., 1970; Madden, 1977). Rapid- and slow-growing trunks (Fig. 4) showed a slow process of increase (135 to $335 \mathrm{kPa}$ ) in cambial strength as the season advanced from mid-July to September. This is a common phenomenon that has been observed by other researchers. Fridley et al. (1970) also reported a continual strength increase from June to January in almond, prune, and peach. In eucalypts, the cambial strength in the summer was either significantly higher or not different from winter and the spring values were always lower than the summer (Moor and McMahon, 1986). The lack of negative relationship between cambial strength and cambial growth was further illustrated by a regression analysis for rapid- and slowgrowing trunks during July to September (Fig. 5). They did not show a reciprocal relationship between cambial strength and growth rate as expected, but in fact showed a nonsignificant positive trend.

Branches (Fig. 6a) also exhibited a large cambial strength increase during the growing season. Branch growth rates were low in March and then increased through mid-June and then declined (Fig. 6b). During the clearly increasing phase of growth rate, cambial strength did not decrease. but rather showed an increasing trend. Also, while cambial growth rate was at a minimum $(0.01$ $\mathrm{mm} \cdot \mathrm{day}^{-1}$, March to April and August to September) the strength was low (345 kPa) at one time (March to April) and high $(690 \mathrm{kPa})$ at the other (August to September). Therefore, the seasonal increase in cambial strength that was observed in branches and trunks clearly had no relation to the rate of growth in the cambial zone.

Cambial strength measurements usually showed a range of tree to tree variability of about \pm 10 to $\pm 50 \mathrm{kPa}$ around the mean in daily fluctuations. These fluctuation patterns did not show any strong or consistently significant relationship to fluctuations in growth rate, diurnal shrinkage, air temperature, vapor-pressure deficit, or evapotranspiration. Brown et al. (1987) also showed a variability ranging from \pm 10 to $\pm 100 \mathrm{kPa}$ about the mean for a given moisture content, and a similar scatter was reported for the data obtained by Fridley et al. (1970) on cambial strength and moisture content. This high variability may be a common phenomenon for the property of bark strength.

In young trees, differential irrigation regimes established a clear progressive treatment separation in tree water status (Fig. 7a), stomatal conductance (Fig. 7a), and, by the end of the growing season, in trunk growth (Fig. 7b). However, these physiological differences were not associated with any change in the magnitude or seasonal pattern of cambial strength (Fig. 7c). Cambial strength fluctuations were common to all three irrigation regimes, and did not show statistically significant differences for 20 out of 21 dates of measurements from May to September. Even for this single date, the cambial strength in the dry and the wet regimes were not statistically different, and the cambial strength in medium regime was statistically lower than both. In the dry regime, cambial strength was the highest on 4 days in the month of September, 

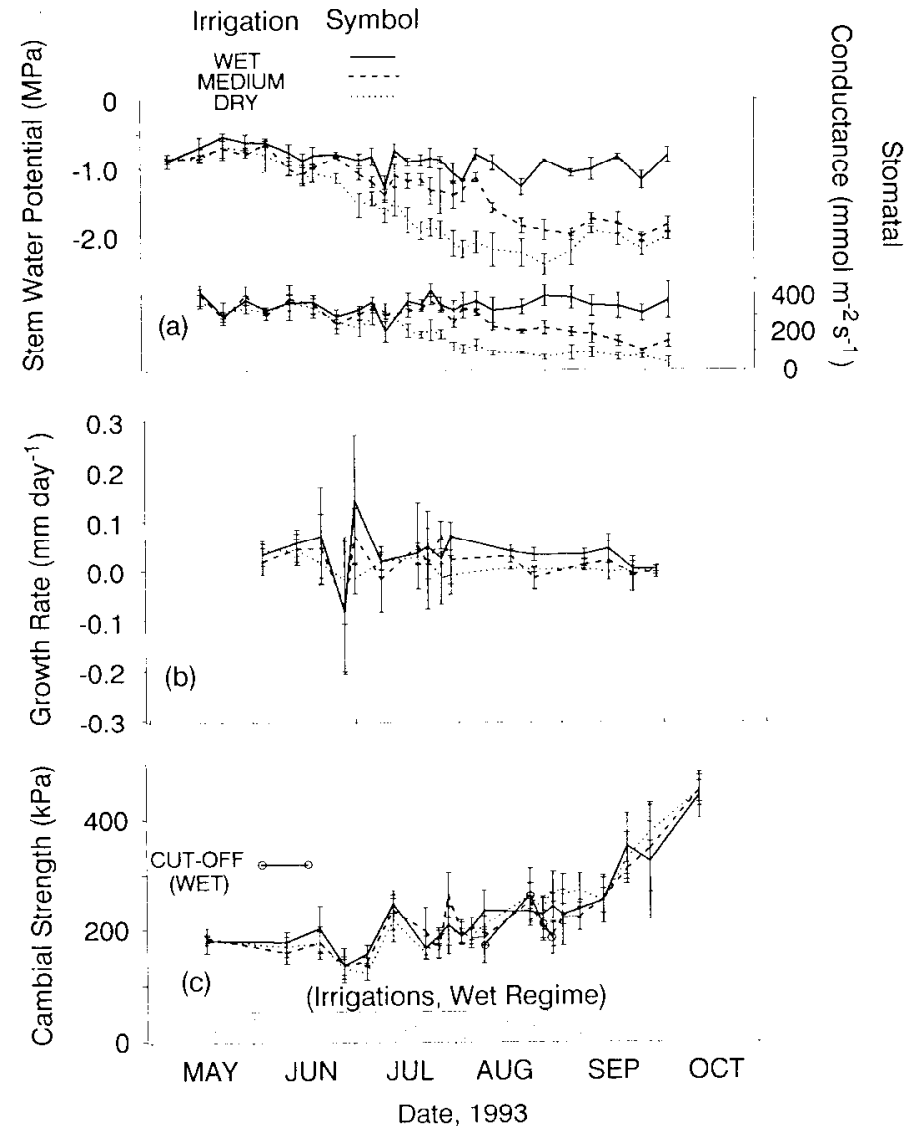

Fig.7. (a) Changes in the midday stem $\Psi$ of almond cultivar 'Nonpareil' in wet, medium and dry irrigation regimes (left, y-axis). One measurement each was taken from four trees in a day. Each bar represents the mean \pm 2 SE for a day. Changes in the leaf stomatal conductance of almond cultivar 'Nonpareil' in wet, medium and dry irrigation regimes (right, y-axis). Four measurements were taken from each of four trees, and a single mean for each tree was calculated. Each bar represents the mean of four trees and its corresponding \pm 2 SE for a day. (b) Changes in the trunk growth rate of almond cultivar 'Nonpareil' in wet, medium and dry irrigation regimen. Two diameter measurements were taken from each of four trees, and an average of the two diameters were calculated. Each bar represents the mean of four trees and its corresponding \pm 2 SE. (c) Changes in trunk cambial strength of almond cultivar 'Nonpareil' in wet, medium and dry irrigation regimesand in a group of wet trees for which irrigation was discontinued (cutoff). One measurement was taken from each tree, and the number of trees measured ranged from 8 to 16 within each treatment for each measurement day. Each bar represents a mean \pm 2 SE for a day. Vertical dotted linen on $\mathrm{x}$-axis, indicate only the dates of Irrigation in the wet regime.

although not statistically different from the trees in the wet regime. Therefore, cambial strength fluctuations were independent from tree water status and tree growth rates (Fig. 7b), despite the fact that tree water stress as well as stomata] conductance in wet and dry regimes had become statistically different for 2 months (Fig. 7a). Cambial strength progressively increased similarly in all treatments as the season advanced (Fig. 7c).

Irrigation cut off in some of the trees in the wet regime near the time of harvest did not increase cambial strength even 28 days after cut off. On 31 Aug., stem $\Psi$ in the wet regime was $-0.9 \pm 0.3 \mathrm{MPa}$ compared to stem $\Psi$ of $1.8 \pm 0.2 \mathrm{MPa}$ in the cut off trees, and the cambial strength in the wet regime $(241 \pm 42 \mathrm{kPa})$ was significantly higher than that of the cut-off trees $(183 \pm 37 \mathrm{kPa})$. All trees, including trees in the irrigation cut off regime, exhibited parallel fluctuations of cambial strength over time. This indicates that irrigation cut off before harvest may have little impact on the dayto-day or seasonal pattern of cambial strength. This may explain the result that Fridley et al. (1970) obtained in prune trees over two irrigation events. Strength measurements 3 days after irrigation were high for both irrigation events, and this observation contradicts the belief that high moisture content lowers the cambial strength. The lowest strength values were observed 12 and 20 days after irrigation of the first drying cycle, but after the second irrigation (9 Aug.) both strength measurements were high soon after irrigation as well as 1 month later. These data support our hypothesis that cambial growth and strength are not negatively related. Fridley et al. (1970) used their data only to illustrate the parallel behavior of total and cambial shear strength.

It is not unreasonable to assume that a negative relationship should exist between cambial strength and cambial growth, since during cell growth new cell wall synthesis processes are believed to be accompanied by cell wall loosening processes (Fry, 1986; McNeil et al., 1980; Roland, 1978). However, the changes in the structural properties of the cambial zone during growth are complex. The weakening effect expected during cell enlargement and cell division may be compensated for by other growth related processes. Rapid growth under wet conditions in the summer should certainly cause vessels and fiber tracheids in the late wood to enlarge before lignification within the differentiating cells in the cambial zone. This could be considered as a weakening effect, as the enlarging xylem vessels cause the deformation and compression in the fiber initials surrounding them (Priestly, 1930). On the other hand, fibers surrounding the enlarging wall could act as strengthening members, counterbalancing the weakening effect due to the enlarging vessels.

During the resumption of meristematic activity at the onset of the spring, the sudden change in the thickness of the cell walls (Esau, 1965; Robards and Kidwai, 1969: Villalba, 1985) may be accompanying a relatively pronounced change in the cambial strength. While the walls of the active cambial cells are thin (radial 0.3-1.0 $\mu \mathrm{m}$; tangential, $0.06-0.3 \mu \mathrm{m}$ ), those of the resting cells are comparatively thick $(2.0-3.0 \mu \mathrm{m}$ and $0.1-0.7 \mu \mathrm{m}$ respectively) (Robards and Kidwai, 1969). Therefore, the fact that growth resumption in the spring causes a rapid decline in the cambial strength may be related to a rapid change in the wall thickness of the cambial zone as a whole in preparation for spring growth, which may be initiated by rapid changes in endogenous growth regulators (Little and Wareing, 1981; Savidge and Wareing, 1984).

Steady cambial growth could involve a number of weakening and strengthening processes. The successive steps in the formation of new tangential walls and junctions with old radial walls in the dividing cambial cells have been studied in detail by Catesson and Roland (198 1). They observed the initial formation of a tangential cell plate, which thickens gradually and its extremities enlarge into a buttress-like zone just before joining the existing radial wall. They reported that at this moment the radial walls display no alteration but eventually the radial wall junctions begin cell wall dissolution and intra-wall rearrangements (Catesson and Roland, 198 1; Funada and Catesson 1991). Catesson and Roland (1981) suggested that this enlarged buttress-like zone at the joint appears as a strengthening zone before the characteristic cell wall dissolution. Therefore, the strength of an entire tissue may not be affected by localized cell wall dissolution and rearrangement in radial wall junctions where old and new walls meet. These arguments support the idea that growth leading to weakening of cambial strength may be too simplistic.

\section{Conclusions}

During the growing season. the rate of cambial growth apparently has no relation to cambial strength in almond trunks, particu- 
larly not a negative relation where low cambial strength is associated with high growth rates.

Neither irrigation cut off nor progressive irrigation deficits were able to influence progressive seasonal changes in cambial strength, despite clear physiological effects on tree water status and tree growth.

These results indicate that irrigation cutoff may be ineffective for the practical purpose of increasing cambial strength and reducing shaker damage.

\section{Literature Cited}

Bradford, K.J. and T.C. Hsiao. 1982. Physiological response to moderate water stress, p. 263-324. In: O.L. Lange, P.S. Nobel, C.B. Osmond, and H. Ziegler (eds.). Encyclopedia of plant physiology. new series. vol 12 B. Physiological ecology. II. Water relations and carbon assimilation. Springer Verlag, Berlin.

Brown, G.K., J.R. Frahm, L.J. Segerlind, and B.F. Cargill. 1987. Bark strengths and shaker pads vs. cherry bark damage during harvesting Trans. Amer. Soc. Agr. Eng. 30(5): 1266-1271.

Burton, V.L.. N.L. Schulte-Parson, G.K. Brown, and D.E. Marshall. 19X6. Inflence of mechanical harvesting on cherry tree declineProgress report. Amer. Soc. Agr. Eng. (St. Joseph, Mich.) paper no. X61559.

Catesson, A.M. and J.C. Roland. 1981. Sequential changes associated with cell wall formation and fusion in the vascular cambium. IAWA. Bul. n.s. 2(4):152-162.

De Vay, J.E, H. English, F.L. Lukezic, and H.J. O'Reilly. 1960. Mallet wound canker of almond trees. California Agr. 14(8):8-9.

De Vay, J.E., F.L. Lukezic, H. English, E.E. Trujillo, and W.J. Moller. 196X. Ceratocystis canker of deciduous fruit trees. Phytopathology 58:949-954.

Diener. R.G., J.H. Levin, and B.R. Tennes. 1968. Directional strength properties of cherry apple and peach bark and the influence of limb mass and diameter on bark damage. Trans. Amer. Soc. Agr. Eng. 11(6):788791.

Dinwoodie, J.M. 1981 Timber its nature and behaviour. Van Nostrand, New York.

Einspahr. D.W., R.H. Van Epren, and M.L. (Harder) Fiscus. 1984. Morphological and bark strength characteristics important to wood/bark adhesion in hardwoods. Wood and Fiber Sci. and Tech. 16(3):339-348.

Esau. K. 1965. Plant Anatomy 2nd Ed. Wiley, New York.

Fiscus, M., R.H. Van Eperen, and D.W. Einspahr. 1983. Method for obtaining wood/bark adhesion measurements on small samples. Wood Fiber Sci. 15(3):219-222.

Fobes, E.W. 1957. Bark peeling machines and methods. U.S. For. Prod. Lab. Publ. no. 1730:48

Fridley. R.B., G.K. Brown, and P.A. Adrian. 1970. Strength characteristic of fruit tree bark. Hilgardia 40(8):205-222.

Fry, S.C. 1986. Cross-linking of matrix polymers in the growing cell walls of angiosperms. Annu. Rev. Plant Physiol. 37:165-86.

Funada, R. and A. Catesson. 1991. Partial cell wall lysis and the resumption or meristematic activity in Fraxinus excelsior cambium. IAWA Bul. n.s. $12(4): 152-102$.

Gurusinghe, S.H. 1994. The effects of irrigation, tree growth and ethephon on the mechanical strength of the cambial zone in almond trees [Prunus dulcis (Mill.) Webb.]. PhD diss. Univ. of California, Davis.

Kozlowski, T.T. 1968. Water deficit and plant growth. Academic Press. New York.

Little, C.H.A. and P.F. Wareing. 1981. Control of cambial activity and dormancy in Picea sitchensis L. by indol-3-ylacetic and abscisic acids. Can. J. Bot. 59:1480-1493.

Madden, J.L. 1977. Direct evaluation of cambial activity in trees. Austral. For. Res. 7: 145-150.

McNeil, M., A.G. Darvill, and P. Albersheim. 1980. The structural polymers of the primary walls of dicots. Prog. Chem. Organic Natural Prod. 37:191-250.

McCutchan, H. and K.A. Shackel. 1992. Stem-water potential as a sensitive indicator of water stress in prune trees (Prunus domestica L. cv. French) J. Amer. Soc. Hort. Sci. 117(4):607-611.

Moor, G.A. and T.A. McMahon. 1986. Bark/Wood bond strength and its association with material and environmental variables. Wood and Fiber Sci. 18(4):526-536.

Philipson, W.R. and J.M. Ward. 1965. The ontogeny of the vascular cambium in the stem of seed plants. Biol. Rev. 40:534-579.

Priestly, J.H. 1930. Studies in the physiology of cambial activity III: The seasonal activity of the cambium. New Phytologist 26:316-54.

Priestly, J.H., J.L. Scott, and M.E. Mulins. 1933. A new method of studying cambial activity. Proc. Phil. Lit. Soc. 2:365-374.

Robards, A.W. and P. Kidwai, 1969. A comparative study of the ultra structure of resting and active cambium of Salix fragilis. L. Planta (Berl.) 84:239-9249.

Roland, J.C. 1978. Early differences between radialwalls and tangential walls of actively growing cambial zone. IAWA Bul. 1:7-10.

Savidge, R.A. and P.F. Wareing. 1984. Seasonal cambial activity and xylem development in Pinus contorta in relation to endogenous indo3-ylacetic and (S)abscisic acid levels. Can. J. For. Res. 14:676-682.

Schutt, C. 1960. Chemical debarking of trees: A reveiw of literature. Paperi. ja. Puu. 11:79-598.

Verner. L.. W.J. Kochan. D.O. Ketchie, A. Kamal, R.W. Braun, J.W. Berry, Jr., and M.E. Johnson. 1962. Trunk growth as a guide in orchard irrigation. Univ. of Idaho Res. Bul. 52:1-32.

Villalba. R. 1985. Xylem structure and cambial activity in Prosopis flexuosa D.C. IAWA Bul. n.s. 6(2):119-130

Wilcox, H.E., F.J. Czabator, and G. Girolami. 1954. Season variations in bark peeling characteristics of some Adirondack pulpwood species. J. For. 52(5):33X-342. 